him realise that the value of a digit depended upon its position, and that the zero was simply a shorthand symbol for an empty place. His coloured thinking satisfied me that I had completely succeeded, and that the cipher o was really nothing to him.

I note that Miss A. M. sees 20,30 , 40, etc., coloured as $2,3,4$, etc.; but since, apparently, 20-29 are coloured as 2, 30-39 as 3 , and so on, there is no such inference possible in her case. It would, however, be of interest to learn whether she sees o coloured or not.

There was one exception to this nonentity of zeros in my son's mind; for he described rooo as always yellow, adding that "it ought to be black really [i.e. the colour of I], but it is not; that's the funny thing; it does not come in proper order." My interpretation was that a thousand seemed to him something so big and important that it stood by itself and rather out of relation to the lower numbers; and I suspect that, had he known it only as "ten hundred," it would have been duly black.

It will be observed that, although on the earlier occasion he gave no specific colours to I and 2, yet his colours for Io, II, and I2 accorded pretty well with the colours assigned on the second occasion to $I$ and 2. Otherwise there is no discrepancy between the two records.

I obtained from him also the colours of the points of the compass, of the names of various towns and countries, and of sundry other names; but too much space would be occupied by the account and discussion of these. He told me that "nearly everything I can think of is coloured."

My daughter similarly has coloured concepts; but she has also what I do not remember ever to have seen described in anyone else until I read Prof. Harris's letter, and that is coloured tastes. I think, too, that tastes are more strongly coloured for her than for Miss A. M. She has frequently, to our amusement, spoken of things having "a mauve taste"; and when we were discussing coloured thinking last vacation she remarked that "of course all tastes are coloured."

Prof. Harris emphasises the normally hereditary character of coloured thinking. A few words have always been coloured for $\mathrm{me}$, and in a vague and misty way many probably are; but if I try to see (mentally) what precisely the colours are, I cannot succeed. It seems rather as though some words had polished or glitterins surfaces, or a sheen, and reflected light, while others were sombre and light absorbent. When I read Galton's book about thirty years ago I realised that I saw the numerals in a psychogram.

My wife, after declaring that coloured thinking was utterly unintelligible to her, mentioned that, of course, the vowels are coloured, and that she had supposed they were for everyone, but that the consonants are not. It appears, therefore, that my children started from a slight, but twofold, hereditary tendency to coloured thinking.

Polperro, Cornwall, February iz.

\section{The Effects of Oil from Ships on Certain Sea-birds.}

Sir ArThur E. ShIPley has recently directed attention to the probable effects upon our fisheries of the discharge of oil from ships into the sea. I should like to refer to another side of this matter, viz. the effects upon certain species of sea-birds.

For our present purpose we may divide sea-birds into three groups according to the number of eggs NO. 2678 , VOL. IO6] they hatch per season, and, further, in each group we may distinguish certain species as divers. All, I believe, are single-brooded.

In the first group we have those species which hatch a single egg each season, such as the petrels, fulmars, sherewaters, and the razorbill, kittiwake, guillemot, little auk, puffin, etc. In the second group are the terns and the great northern and black- and red-throated divers, usually hatching two eggs per season. With the exception of the cormorant and the shag, Group 3 consists of the more littoral species (chiefly Laridæ), which produce three or more eggs per season, and scarcely bear upon the present subject.

During the past five years large numbers of those species which dive beneath the surface of the water in order to obtain their food have been washed up on the Fife coast and elsewhere dead or in a dying condition and covered with a thick coating of oil. The actual total of dead birds must be enormous. In one day we counted more than 300 kittiwakes and almost the same number of razorbills and guillemots, and dozens of little auks and puffins, and this is of frequent occurrence. On the west sands at St. Andrews in October last dozens of dead gannets in a similar condition were washed ashore. Even admitting that these represent a concentration from a great sea area, the oft-repeated occurrence indicates a new factor of disturbance which is proving inimical to a large percentage of these birds. If this continues, or the disturbing factor grows more serious, the possibility of the extermination of such species seems not at all unlikely.

It is a generally accepted biological principle that the rate of reproduction of a species is a character very slow to change, and in the case of slow breeders, such as the species here referred to, any unusual factor leading to a higher rate of mortality can only lead to very serious consequenats.

The University, St. Andrews.

$$
\text { Walter E. Collinge. }
$$

\section{The Annular Eclipse of the Sun on April 8.}

As the annular eclipse of the sun on April 8 next may be of considerable interest to amateur observers, I am preparing a list of observations which may be made both within and without the region of annularity, and also full instructions for making the observations. Should any readers of NATURE care to suggest observations which might be made with small telescopes and the equipment generally possessed by an amateur, I should be very glad to receive their suggestions. May I also add that I am proposing to observe the eclipse from a point near the central line (probably Benbecula, in the Outer Hebrides), and if other amateurs would care to join me, would they please communicate with me with the view of forming a party?

The Priory, Royston, Herts, February 2.

\section{A Rare Example of Melanism.}

I would like to record the occurrence of a rare case of melanism. Mr. Carl Carinus, in Rhodesia, sent me the complete skin and skeleton of an adult female oribi. It was entirely black, without any trace of white or red. The female was in the company of an adult male of normal colour.

F. W. FrtzSimons.

Port Elizabeth Museum, Port Elizabeth, January 27 . 